\title{
Psychological Aspects of Bariatric Surgery as a Treatment for Obesity
}

\author{
Sandra Jumbe ${ }^{1}$ - Claire Hamlet ${ }^{2} \cdot$ Jane Meyrick $^{3}$ \\ Published online: 27 February 2017 \\ (C) The Author(s) 2017. This article is published with open access at Springerlink.com
}

\begin{abstract}
Purpose of Review Little is known about the psychological effects on life after bariatric surgery despite the high prevalence of psychological disorders in candidates seeking this procedure. Our review discusses the literature around the psychological impact of bariatric surgery, exploring whether the procedure addresses underlying psychological conditions that can lead to morbid obesity and the effect on eating behaviour postoperatively.

Recent Findings Findings show that despite undisputed significant weight loss and improvements in comorbidities, current literature suggests some persisting disorder in psychological outcomes like depression and body image for patients at longer term follow-up, compared to control groups. Lack of postoperative psychological monitoring and theoretical
\end{abstract}

This article is part of the Topical Collection on Psychological Issues

Sandra Jumbe

S.Jumbe@qmul.ac.uk

Claire Hamlet

Claire.Hamlet@uwe.ac.uk

Jane Meyrick

Jane.Meyrick@uwe.ac.uk

1 Centre for Primary Care and Public Health, Blizard Institute, Queen Mary University of London, Yvonne Carter Building, 58 Turner Street, London E1 2AB, UK

2 Centre for Appearance Research, Department of Health and Social Sciences, University of the West of England, Frenchay Campus, Coldharbour Lane, Bristol BS16 1QY, UK

3 Department of Health and Social Sciences, University of the West of England, Frenchay Campus, Coldharbour Lane, Bristol BS16 1QY, UK mapping limits our understanding of reasons behind these findings.

Summary Reframing bariatric approaches to morbid obesity to incorporate psychological experience postoperatively would facilitate understanding of psychological aspects of bariatric surgery and how this surgical treatment maps onto the disease trajectory of obesity.

Keywords Bariatric surgery · Psychological health . Postoperative outcomes · Obesity

\section{Introduction}

Obesity is a major health problem worldwide and has reached epidemic proportions in both developed and developing countries $[1,2]$ making it an extremely important public health issue. Clinically defined in terms of body mass index (BMI), a person is considered obese if their BMI is above $30 \mathrm{~kg} / \mathrm{m}^{2}[3,4]$. Evidence shows obesity as a major risk factor for significant morbidity and mortality [5] including diabetes mellitus, cardiovascular disease [6], non-alcoholic fatty liver disease [7], reduced lung function [8-10] and increased risk of cancers [11, 12]. The condition can also present negative psychological impact resulting in social stigma, mental health and self-esteem issues [13, 14], and poorer quality of life [15].

Bariatric surgery defines a group of surgical procedures performed to facilitate weight loss; open or laparoscopic roux-en-Y gastric bypass (RYGB), sleeve gastrectomy (SG) and adjustable gastric banding (AGB) being the most commonly performed procedures worldwide $[16,17]$. There has been an increasing amount of evidence for bariatric surgery as a more effective treatment for morbid obesity $[2,18,19]$ compared to dietary advice, exercise, lifestyle changes and medication. In particular, the procedure is more effective in achieving significant weight 
loss, longer term maintenance, improvements in co-morbidities and reductions in mortality such as physical activity and diet $[20$, 21]. This growing evidence of the benefits of bariatric surgery has contributed to increased popularity of the procedure over the last decade [22] and led some obesity experts to see the procedure as the solution to the looming obesity epidemic [23]. However, there has been a limited focus in research around the psychological outcomes of bariatric surgery [24]. It is important to consider the psychological effects of these procedures not only in order to optimise their outcome but also to frame the condition in terms of its psychological context, to better understand what leads to morbid obesity and therefore what can prevent or treat the condition.

\section{Theoretical Models in the Aetiology of Obesity}

Currently, there is a general lack of theoretical understanding of what causes and maintains morbid obesity [25] as the aetiological basis of the behaviours that lead to obesity are very complex, including a combination of psychosocial, environmental and biological influences [26, 27]. The question for health psychologists is whether physiological approaches to weight loss, such as bariatric surgery, need to also address underlying psychological conditions that can lead to morbid obesity. Crucially, psychological issues can lead to individuals experiencing difficulty controlling their food consumption and exercising adequately $[28,29 \bullet]$, resulting in the onset and maintenance of obesity, but what is the mechanism behind this pathway?

Theoretical models of the condition are not well developed, but a few useful approaches are covered here. In the realm of addiction theory, obesity has been conceptualised as a consequence of addictive behaviour akin to substance abuse. For instance, an individual is seen as having an 'impaired control over a reward-seeking behaviour (usually drug-taking) from which harm ensues' which presents itself in varying extents [30,31]. Addictive drugs are said to hijack the brain's reward system by binding to receptor sites that produce intense feelings of pleasure [32]. When this approach is transposed in the context of obesity, highly palatable (or junk) foods are framed as the 'drugs' that takeover the individual's brain reward system, leading to weight gain due to continuous consumption of the junk food, reinforced by pleasurable sensations following dopamine release over time [33].

However, addiction has longstanding negative connotations mostly linked to historically social perceptions of drug addicts as deviants to stability and morality [34]. Therefore, the 'food addict' label may stigmatise the obese population as disordered individuals, lacking in self-control [35]. Critics of the addiction approach to obesity have importantly questioned the validity of framing food as an illicit drug [36]. Is it useful to label something as socially embedded in this light, particularly when consumption of junk food is not limited to the obese? However, as pointed out by Schulte and colleagues [37•] if certain foods (e.g. highly processed) are addictive, the identification of possible risk factors for food addiction is key to recognising this. Importantly, this theoretical approach frames behaviour as changeable because internal and external environments directly influence it in a continuously erratic manner [31]. This aptly reflects the variable nature of eating behaviour. Moreover, it shows how challenging it is to tackle overeating and inactivity by using approaches like gradual decision making and action plans, which assume that behaviour change occurs in a linear manner when we know that the factors that trigger motivation to engage in healthy behaviour do not follow a linear fashion [38].

Another theoretical focus in obesity has been on eating as a habitual coping mechanism, drawing attention to the various ways in which past experiences influence our behaviour. Studies indicate that habit strength adds considerably to the extent of variance in healthy eating behaviours across a range of age groups [39]. This implies that a key reason why longterm behaviour change may be difficult for the obese population is that the behaviours that individuals want to change like poor dietary habits and limited physical activity are relatively habitual. Consequently, researchers are working to further understand the role of these concepts in eating behaviours [40, 41] in order to develop effective cue-exposure treatments that potentially decrease food cue reactivity and urges to overeat [42].

In the context of bariatric treatment, research shows that bariatric surgery candidates take longer to be satiated due to slower salivary habituation to food and taste stimuli compared to normal-weight individuals [43] which may influence greater caloric or energy intake. However, bariatric surgery seems to trigger a change in eating behaviour, particularly changes in taste response where patients find sweet and fatty meals less pleasant, which facilitates adoption of healthier foods and subsequent weight loss $[44,45]$. Habituation theory therefore may be a useful tool for helping our understanding of eating regulation in morbid obesity and the mechanisms behind postsurgical changes in taste. This could potentially aid development of novel weight loss maintenance interventions following bariatric surgery.

A more recent theoretical model of obesity incorporating biological, psychosocial and environmental factors has been proposed by Marks [29•]. This suggests that the overconsumption of high-calorific, low-nutrient and low-satiating foods, combined with a stressful environment, is the origin of weight gain. Once that weight gain occurs, an individual experiences body dissatisfaction and negative affect leading to continued over-consumption over a prolonged period. This dysfunctional state leaves individuals unable to control weight gain and subsequently forms a vicious 'Circle of Discontent' (Fig. 1). 


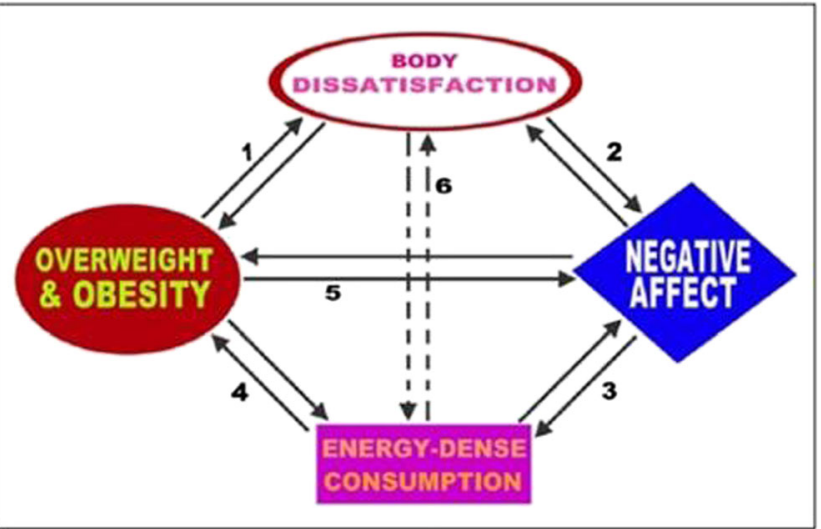

Fig. 1 The Circle of Discontent. Reproduced with permission from Marks [29•]

This Circle of Discontent (COD) highlights the important role of body image along its pathway, particularly how general negative affect (depression, low self-esteem) is associated with body dissatisfaction, patterns of consumption and directly with weight status. Although comfort eating may result in temporary reduction in distressed mood, the weight gain that follows may cause a dysphoric mood due to an inability to control one's distress and subsequent feelings of guilt may reactivate the cycle, leading to a continuous pattern of using food to cope with emotions. This pattern is particularly applicable if there is a genetic predisposition for obesity or an environment in which calorically dense foods are readily available and physical activity is limited [46]. An interpersonal dimension of obesity is also introduced to this model, by highlighting that general negative public perception of large body size makes larger individuals more likely to be dissatisfied with their own body [47] underpinning isolation and a general lack of social support. Furthermore, Marks also outlines the influential role significant others have on one's eating behaviour through his consideration of the role of attachment and parenting which highlights a need to understand obesity and its onset from a life span perspective [48-50].

The notion of behaviour being regulated by homeostasis where people should be motivated to eat when hungry and stop when satiated is intuitive, but many people find it challenging to regulate their eating behaviours and to sustain this over a long period of time. A key aspect of tackling obesity is determining the psychological factors that make some individuals more resilient to relapse after initiation of behaviour change (such as autonomy and competency) and how these processes relate to motivation to regulate eating behaviour over time [51, 52]. Even though this has not been specifically addressed in Marks' COD model, his model highlights this notion of habitual coping which develops over time and the role of life span, suggesting that more consideration of patients and their eating behaviour across the life course may be of use. This raises food for thought as his time frame contrasts with the time-limited approach of bariatric interventions to treat morbid obesity. Furthermore, addressing alternative coping mechanisms beyond the potential of comfort eating requires investigation.

Overall, the outlined theories highlight gaps in the theoretical domain of obesity which as a consequence limit the development of a wider range of health interventions that may work effectively over the long term. In addition, there is a need to understand the function eating behaviour serves for obese individuals in order to redefine or replace this behaviour after bariatric surgery.

\section{Psychological health in bariatric surgery candidates}

It is clear that the development and maintenance of morbid obesity is psychologically complex. However, not everyone living with morbid obesity will opt for bariatric surgery as a method of weight loss, even if they are eligible. This has prompted further research into the psychological co-morbidities of those opting for bariatric surgery. Specific literature on bariatric surgery indicates a higher prevalence of psychological co-morbidities such as mood disorders, eating behaviour disorders and psychological distress in bariatric surgery candidates $[53,54]$ along with anxiety, personality disorders, alcohol use and low self-esteem when compared to controls or other obese patients who do not seek the procedure [55-57].

Psychological screening before bariatric surgery is commonly used to identify potential contraindications to surgery and additional education or psychological need before surgery, in order to optimise outcomes [58]. However, there has been controversy around active exclusion of bariatric surgery candidates due to psychiatric disorders, with researchers pointing out that these individuals could still experience improvement of health status and well-being postoperatively if adequate support is provided after bariatric surgery [59].

It is important to understand the relationship between obesity and mental health. Despite the greater effectiveness of bariatric surgery compared to other obesity interventions in relation to improved medical outcomes [19], research around persisting psychological issues after surgery is sparse. This may be due to a general lack of postoperative psychological monitoring, in contrast to the amount of screening for psychological disorder and risk before the procedure. Assessing psychological outcomes after surgery in this patient group is important in order to effectively evaluate whether this surgical treatment approach can facilitate resolution of pre-existing psychological conditions that may support recovery. This paper describes three psychosocial outcomes of bariatric surgery, namely psychosocial health, eating behaviours and body image. These outcomes have been selected because of their prevalence in bariatric surgery candidates and the potential influence they have on weight loss success and maintenance. 


\section{Impact of bariatric surgery on psychosocial health}

Research has reported improvements in psychosocial status following bariatric surgery including social relations and employment opportunities [60], and improved quality of life [61]. However, although evidence from recent systematic reviews in this area shows that the surgery can result in drastic weight loss and maintenance [19], most of this data is limited to the first 2-3 years of postsurgery follow-up [62・•]. Specifically looking at depression, De Zwaan and colleagues [63] investigated the course of anxiety and depressive disorders in 107 extremely obese bariatric surgery patients using face-to-face interviews conducted before surgery and postoperatively at 6-12 months and 24-36 months. Although prevalence of depressive disorders decreased significantly after surgery in their cohort, participants with both depressive and anxiety disorders at baseline lost significantly less weight after surgery. Moreover, postoperative depressive disorder was negatively associated with weight loss at 24-36-month follow-up. Overall, their suggested that presence of depressive disorders after bariatric surgery significantly predicted attenuated postsurgical improvements, inferring a need for clinical attention where postoperative depression is present. More recent research investigating the impact of bariatric surgery on depression has found modest reductions over the initial postoperative years i.e. approximately 2 years [64, 65]. However, subsequent elevations in depressive symptoms in longer term follow-up [64, 66].

Further longer term studies suggest minimal improvements in mental components of quality of life and psychosocial wellbeing after surgery compared to behavioural interventions and usual care despite overall significant improvements in physical quality of life, weight loss and co-morbidities [62••, 67•]. This finding of persistent mental health problems, regardless of weight loss, compared to counterparts who received behavioural intervention as morbid obesity treatment, suggests a subset within the bariatric surgery patient community that do not do well psychologically despite generally positive medical and physiological outcomes [62・•, 24]. Moreover, this evidence emphasises the need for further research in this area to provide more comprehensive understanding of long-term psychological well-being postsurgery.

\section{Impact of bariatric surgery on eating disorders}

Studies have shown that eating problems like Binge Eating Disorder (BED) have a prevalence of 10 to $27 \%$ in pre-surgical candidates $[68,69]$. Another eating disorder found to be more prevalent amongst this population is Night Eating Syndrome (NES), a core feature of which is a shift in the circadian pattern of eating, resulting in frequent night awakenings linked to nocturnal eating and morning anorexia [70]. As bariatric surgery imposes a physical change in individuals' ability to consume large quantities and types of food, an important element may be how the procedure affects the complex pattern of eating behaviour. Research implies that the procedure triggers biological changes in the release of gastrointestinal hormones that control appetite which could in turn influence eating behaviour postoperatively [71].

Some studies have found that BED prevalence in presurgical candidates persists after bariatric surgery with patients showing either a return to loss of control over eating and binge eating [72, 73], development of frequent eating, labelled 'grazing' [74] which as a consequence negatively affect weight loss and weight loss maintenance following bariatric surgery [55, 72]. Interestingly, Wood and Ogden [75] who looked at binge eating behaviour before and after gastric banding in 49 patients found that decreased binge eating as a consequence of having surgery significantly predicted postoperative weight loss. They suggested that the procedure possibly facilitates a change in cognitions relating to food by changing the association between emotions and food. Other studies have similarly described lower hedonic responses to food after surgery, attributing it to lower activation in the brain reward system outlined in the addiction theory [76] and changes in taste perception [77]. Wood and Ogden [78] subsequently identified behavioural intentions as key predictors of reduced binge eating after surgery. This suggests that individuals who present with binge eating at preoperative screening could optimise positive weight loss outcomes if interventions focused on increasing preoperative levels of intention to follow the postoperative eating guidelines.

Studying the impact of NES on bariatric surgical outcomes is similarly important, as postoperative continuation of this eating disorder may hamper weight loss success or maintenance. Despite its high prevalence amongst bariatric surgery candidates, research looking at postsurgical continuation or change in NES-related behaviour is limited [79]. A recent review on NES in bariatric surgery patients implied a decrease in symptoms of NES after weight loss surgery [80]. De Zwaan and colleagues also found no evidence for negative impact on weight loss following surgery due to pre-surgery NES. However, several limitations were noted, such as inconsistency in diagnostic criteria. Moreover, very few studies examined night eating prospectively or followed samples long enough after bariatric surgery to fully examine the impact of NES. Ultimately, more prospective and longitudinal studies looking at the course of this eating disorder, using clear criteria and standardised assessment instruments, are required.

\section{Impact of bariatric surgery on body image}

Body image is a multifaceted construct defined as 'one's body-related self-perceptions and self-attitudes, including thoughts, beliefs, feelings and behaviours' [81]. One construct, body image dissatisfaction, defined as a persons' negative thoughts and feelings about his or her body [82], is 
reported as one of the most consistent outcomes of obesity. As previously noted, body image dissatisfaction is positively associated with increased BMI $[83,84]$ and related to issues such as binge eating and overestimation of body size in obese populations [85]. As such, it is reported as a key motivator for seeking bariatric surgery, especially amongst women [86]. Bariatric surgery has the potential to improve a person's body image because weight loss is capable of moving them closer to societies prevailing slim ideal. However, the procedure can result in significant changes to appearance such as scarring, sagging skin and soft tissue excess [87] which can in turn, significantly impact upon a individual's body image.

Despite the significant changes to appearance following bariatric surgery, the impact it has upon patients' body image has received little attention. Existing research reports positive effects of bariatric surgery upon body shape preoccupation [88-90] body image quality of life [91] attitude towards one's body [92] and satisfaction with one's appearance [91]; however, these body image improvements often fail to reach population norms [92, 93]. If negative constructs of body image, such as body dissatisfaction, are positively associated with $\mathrm{BMI}$, it is logical to assume that body image improvements would be related to the amount of weight loss. Indeed, satisfaction with one's appearance [88] and body image quality of life [94] have been positively correlated with the amount of weight loss. Whilst De Panfilis [95] found that the reduction in body image dissatisfaction observed in their sample of morbidly obese patients did not involve concomitant weight loss, they also found other mediating factors, such as binge eating behaviour, were influential. It appears that body image improvement could be related to patients' changing attitudes or behaviours following surgery, rather than actual weight loss, but additional investigation to clarify this is required.

Much of the literature reporting improvements in body image investigate short-term changes typically within 2-year postbariatric period [94]. Research that investigates longer term body image after bariatric surgery is important, as rapid weight loss occurs in the first 6 months and then slows down or is even regained [96] after which body image improvements could cease, or concerns could return or change focus. Perhaps one key indicator of long-term postoperative body dissatisfaction is the large number of patients who request body contouring surgery to ameliorate functional and/or aesthetic concerns most commonly related to excess skin. Such concerns can be a long-term burden due to the notable disparity between those who desire it and those that receive it [97]. Body contouring is reported to improve body image following bariatric surgery $[87,97,98]$. However, patients can have high expectation of contouring procedures to improve their appearance [98] and body dissatisfaction may shift to a different part of the body after the procedure. For example, Song and colleagues found that after contouring, body image satisfaction in patients improved regionally, particularly where treatment occurred. This resulted in a shift in body dissatisfaction focused towards previously hidden areas of deformity or other untreated areas that looked visibly disproportionate to the contoured areas [87].

\section{Conclusions}

The literature reviewed suggests that despite drastic weight loss and positive physical health improvements experienced postoperatively over time, some psychological problems, probably linked to a disordered relationship with food [55, $72,73,99]$ present in obese individuals from onset, remain. The findings also highlight the importance of identifying risk groups among bariatric surgery patients who may require additional support with dietary and psychological follow-up $[100 \bullet \bullet$.

The superiority of bariatric surgery in improving medical outcomes of the severely obese when compared to other weight reduction interventions remains undisputed [18, 19]. However, at present, our understanding of psychological health outcomes following bariatric surgery is limited. A key reason for this may be the acute biomedical nature in which this surgical intervention for morbid obesity is delivered and assessed. This might be because bariatric surgery and its outcomes are still very much framed within a surgical perspective, making psychological outcomes and time frames less of a priority [101]. This approach seems to contrast with the onset of obesity within the biopsychosocial framework of not only biological attributes but also psychosocial and environmental factors.

A general lack of postoperative psychological follow-up means that very little is known about the effect bariatric surgery has on patients' psychological outcomes. This is unfortunate considering the array of postsurgical psychosocial challenges the procedure elicits as a result of drastic weight loss and other physiological changes [102], namely body image concerns, mood changes, stress, substance use [94] and weight regain [103]. Research addressing patients' psychological postoperative needs could reduce the risk of weight regain [104] and optimise the effect of the procedure itself. On a broader level, research that considers the long-term outcomes beyond 2 years is needed to better understand how psychology and surgery interrelate within a behaviour that has developed across the life course. Framing this interrelation is crucial, as weight loss and other potentially relevant behavioural changes occur gradually and therefore warrant long-term monitoring.

Finally, existing research into bariatric surgery is generally quantitative, with most outcomes focused on physiological measures such as weight and obesity co-morbid medical issues. Existing psychological research relies heavily on selfreport quantitative data, which does not allow the opportunity to adequately capture detailed insights into the experience of 
having bariatric surgery from a patient perspective, suggesting further requirement for qualitative research. Rigid responses acquired through self-report measures make it difficult to collect data over a long period of time that adequately encapsulates the disease trajectory of morbid obesity alongside psychological experience. This limitation may have led to a lack of theory building around morbid obesity found in this review.

\section{Compliance with Ethical Standards}

Conflict of Interest Sandra Jumbe, Claire Hamlet, and Jane Meyrick declare that they have no conflict of interest.

Human and Animal Rights and Informed Consent This article does not contain any studies with human or animal subjects performed by any of the authors.

Open Access This article is distributed under the terms of the Creative Commons Attribution 4.0 International License (http:// creativecommons.org/licenses/by/4.0/), which permits unrestricted use, distribution, and reproduction in any medium, provided you give appropriate credit to the original author(s) and the source, provide a link to the Creative Commons license, and indicate if changes were made.

\section{References}

Papers of particular interest, published recently, have been highlighted as:

- Of importance

•• Of major importance

1. Ng M, Fleming T, Robinson M, Thomson B, Graetz N, Margono $\mathrm{C}$, et al. Global, regional, and national prevalence of overweight and obesity in children and adults during 1980-2013: a systematic analysis for the Global Burden of Disease Study 2013. Lancet. 2013;384(9945):766-81.

2. Chang S, Stoll C, Song J, Varela J, Eagon C, Colditz G. The effectiveness and risks of bariatric surgery: an updated systematic review and meta-analysis, 2003-2012. JAMA Surg. 2014;149(3): 275-87.

3. Flegal K, Kruszon-Moran D, Carroll M, Fryar C, Ogden C. Trends in obesity among adults in the United States, 2005 to 2014. JAMA. 2016;315(21):2284-91.

4. Flint S, Hudson J, Lavallee D. UK adults' implicit and explicit attitudes towards obesity: a cross-sectional study. BMC Obes. 2015;2(1):1.

5. Song X, Jousilahtib P, Stehouwerc C, Söderbergd S, Onatf A, Laatikainenb T, et al. Cardiovascular and all-cause mortality in relation to various anthropometric measures of obesity in Europeans. Nutr Metab Cardiovasc Dis. 2015;25(3):295-304.

6. Dawber T, Moore F, Mann G. Coronary heart disease in the Framingham Study. Int J Epidemiol. 2015;44(6):1767-80.

7. Fabbrini, E. and Magkos, F. Obesity and the pathogenesis of nonalcoholic fatty liver disease. In: Treatment of the obese patient. 2015; Part 1: 121-135.

8. Salome C, King G, Berend N. Effects of obesity on lung function. Obes Lung Dis. 2013;19:1-20.

9. Salome CM, King GG, Berend N. Physiology of obesity and effects on lung function. J Appl Physiol. 2010;108(1):206-11.
10. Forno E., Han Y., Mullen J. and Celedon J. Meta-analysis of obesity and lung function. Am J Respir Crit Care Med. 2016; 193.

11. Gallagher E, LeRoith D. Obesity and diabetes: the increased risk of cancer and cancer-related mortality. Physiol Rev. 2015;95(3): 727-48.

12. Deng T, Lyon C, Bergin S, Caligiuri MA, Hsueh WA. Obesity, inflammation, and cancer. Ann Rev Pathol Mech Dis. 2016;11: $421-49$.

13. Griffiths LJ, Parsons TJ, Hill AJ. Self-esteem and quality of life in obese children and adolescents: a systematic review. Int J Pediatr Obes. 2010;5(4):282-304.

14. Wang F, Wild TC, Kipp W, Kuhle S, Veugelers PJ. The influence of childhood obesity on the development of self-esteem. Health Rep. 2009;20(2):21.

15. Bryant J, Cooper K, Picot J, Clegg A, Roderick P, Rosenberg W, et al. Diagnostic strategies using DNA testing for hereditary haemochromatosis in at-risk populations: a systematic review and economic evaluation. Health Technol Assess. 2009;13(23): 1-126. doi:10.3310/hta13230. iii, ix-xi.

16. Angrisani L, Santonicola A, Iovino P, Formisano G, Buchwald H, Scopinaro N. Bariatric surgery worldwide 2013. Obes Surg. 2015;25(10):1822-32.

17. Dent M, Chrisopoulos S, Mulhall C, Ridler C. Bariatric surgery for obesity. Oxford: National Obesity Observatory; 2010.

18. Picot J, Jones J, Colquitt JL, Loveman E, Clegg AJ. Weight loss surgery for mild to moderate obesity: a systematic review and economic evaluation. Obes Surg. 2012;22(9):1496-506.

19. Colquitt, J.L., Pickett, K., Loveman, E. and Frampton, G.K. Surgery for weight loss in adults. The Cochrane Library. 2014

20. Gloy VL, Briel M, Bhatt DL, Kashyap SR, Schauer PR, Mingrone G. Bariatric surgery versus non-surgical treatment for obesity: a systematic review and meta-analysis of randomised controlled trials. BMJ: Br Med J. 2013;347:f5934.

21. Ribaric G, Buchwald J, McGlennon T. Diabetes and weight in comparative studies of bariatric surgery vs conventional medical therapy: a systematic review and meta-analysis. Obes Surg. 2014;24(3):437-55.

22. Welbourn, R., Small, P., Finlay, I., Sareela, A., Somers, S. and Mahawar, K. The United Kingdom National Bariatric Surgery Registry. Second Registry Report; 2014.

23. Mechanick JI, Youdim A, Jones DB, Garvey WT, Hurley DL, McMahon MM, et al. Clinical practice guidelines for the perioperative nutritional, metabolic, and nonsurgical support of the bariatric surgery patient? 2013 update: cosponsored by american association of clinical endocrinologists, The obesity society, and american society for metabolic \& bariatric surgery*. Obesity. 2013;21(S1):S1-27.

24. Jumbe, S., Bartlett, C., Jumbe, S. L., \& Meyrick, J. The effectiveness of bariatric surgery on long term psychosocial quality of lifeA systematic review. Obes Res Clin Pract. 2016

25. Markey CN, August KJ, Bailey LC, Markey PM, Nave CS. The pivotal role of psychology in a comprehensive theory of obesity. Health Psychol Open. 2016;3(1):2055102916634365.

26. Blaine B. Does depression cause obesity? A meta-analysis of longitudinal studies of depression and weight control. J Health Psychol. 2008;13(8):1190-7.

27. Singh G, Jackson C, Dobson A, Mishra G. Bidirectional association between weight change and depression in mid-aged women: a population-based longitudinal study. Int J Obes. 2014;38(4):5916.

28. Collins JC, Bentz JE. Behavioral and psychological factors in obesity. J Lancaster Gen Hosp. 2009;4(4):124-7.

29. Marks DF. Homeostatic theory of obesity. Health Psychol Open. 2015;2(1):2055102915590692. This article gives a progressive step toward understanding the complex factors linked to 
obesity, with a comprehensive approach to conceptualising psychological factors.

30. West, R., \& Hardy, A. A theory of addiction. Malden; 2006.

31. West R, Brown J. Theory of addiction. John Wiley \& Sons; 2013.

32. Robinson TE, Berridge KC. Review. The incentive sensitization theory of addiction: some current issues. Philos Trans R Soc Lond Ser B Biol Sci. 2008;363(1507):3137-46.

33. Everitt BJ, Robbins TW. Neural systems of reinforcement for drug addiction: from actions to habits to compulsion. Nat Neurosci. 2005;8(11):1481-9.

34. van Boekel LC, Brouwers EP, van Weeghel J, Garretsen HF. Public opinion on imposing restrictions to people with an alcohol-or drug addiction: a cross-sectional survey. Soc Psychiatry Psychiatr Epidemiol. 2013;48(12):2007-16.

35. DePierre JA, Puhl RM, Luedicke J. A new stigmatized identity? Comparisons of a "food addict" label with other stigmatized health conditions. Basic Appl Soc Psychol. 2013;35(1):10-21.

36. Fraser S. Junk: overeating and obesity and the neuroscience of addiction. Addict Res Theory. 2013;21(6):496-506.

37. Schulte EM, Joyner MA, Potenza MN, Grilo CM, Gearhardt AN. Current considerations regarding food addiction. Curr Psychiatry Rep. 2015;17(4):1-8. This reports provides an update on the concept of food addiction and where the addiction framework fits in as a treatment approach within the context of overeating and obesity.

38. Resnicow K, Vaughan R. A chaotic view of behavior change: a quantum leap for health promotion. Int J Behav Nutr Phys Act. 2006;3(1):1.

39. Raman J, Smith E, Hay P. The clinical obesity maintenance model: an integration of psychological constructs including mood, emotional regulation, disordered overeating, habitual cluster behaviours, health literacy and cognitive function. J Obes. 2013;2013: 240128. doi:10.1155/2013/240128. Epub 2013 Feb 14.

40. Olsen A, Møller P, Hausner H. Early origins of overeating: early habit formation and implications for obesity in later life. Curr Obes Rep. 2013;2(2):157-64.

41. Burger KS, Stice E. Greater striatopallidal adaptive coding during cue-reward learning and food reward habituation predict future weight gain. Neuroimage. 2014;99:122-8.

42. Boutelle KN, Bouton ME. Implications of learning theory for developing programs to decrease overeating. Appetite. 2015;93: $62-74$.

43. Bond DS, Raynor HA, Vithiananthan S, Sax HC, Pohl D, Roye GD, et al. Differences in salivary habituation to a taste stimulus in bariatric surgery candidates and normal-weight controls. Obes Surg. 2009;19(7):873-8.

44. Miras AD, le Roux CW. Bariatric surgery and taste: novel mechanisms of weight loss. Curr Opin Gastroenterol. 2010;26(2):140 5.

45. Mathes CM, Spector AC. Food selection and taste changes in humans after Roux-en-Y gastric bypass surgery: a directmeasures approach. Physiol Behav. 2012;107(4):476-83.

46. Swinburn BA, Sacks G, Hall KD, McPherson K, Finegood DT, Moodie ML, et al. The global obesity pandemic: shaped by global drivers and local environments. Lancet. 2011;378(9793):804-14.

47. Tiggemann M, Zaccardo M. 'Strong is the new skinny': a content analysis of\# fitspiration images on Instagram. J Health Psychol. 2016.

48. Mikulincer M, Shaver P. Boosting attachment security to promote mental health, prosocial values, and inter-group tolerance. Psychol Inq. 2007;18(3):139-56.

49. Faber A, Dubé L. Parental attachment insecurity predicts child and adult high caloric food consumption. J Health Psychol. 2015;20: $511-24$.

50. Molnar D, Sadava S, DeCourville N. Attachment, motivations, and alcohol: testing a dual-path model of high-risk drinking and adverse consequences in transitional clinical and student samples. Can J Behav Sci. 2010;42(1):1-13.

51. Patrick H, Williams GC. Self-determination theory: its application to health behavior and complementarity to motivational interviewing. Int J Behav Nutr Phys Act. 2012;9:18.

52. Teixeira PJ, Silva MN, Mata J. Motivation, self-determination, and long-term weight control. Int $J$ Behav Nutr Phys Act. 2012;9:22.

53. Abiles V, Rodriguez-Ruiz S, Abiles J. Psychological characteristics of morbidly obese candidates for bariatric surgery. Obes Surg. 2010;20(2):161-7.

54. Karmali S. The impact of bariatric surgery on psychological health. J Obes. 2013.

55. Kalarchian MA, Marcus MD, Levine MD. Psychiatric disorders among bariatric surgery candidates: relationship to obesity and functional health status. Am J Psychiatry. 2007;164:328-34.

56. Greenberg I, Sogg SM, Perna F. Behavioral and psychological care in weight loss surgery: best practice update. Obesity (Silver Spring). 2009;17:880-4.

57. Pull CB. Current psychological assessment practices in obesity surgery programs: what to assess and why. Curr Opin Psychiatry. 2010;23:30-6.

58. Block AR, Sarwer DB. Presurgical psychological screening: understanding patients, improving outcomes. 1st ed. Washington, D.C.: American Psychological Association; 2013 (pages 61-83).

59. Peterhänsel C, Wagner B, Dietrich A, Kersting A. Obesity and comorbid psychiatric disorders as contraindications for bariatric surgery? - a case study. Int J Surg Case Rep. 2014;5(12):1268-70.

60. Herpertz S, Kielmann R, Wolf A, Langkafel M, Senf W, Hebebrand J. Does obesity surgery improve psychosocial functioning? A systematic review. Int J Obes. 2003;27:1300-14.

61. Bocchieri LE, Meana M, Fisher BL. A review of psychosocial outcomes of surgery for morbid obesity. J Psychosom Res. 2002;52(3):155-65.

62.• Herpertz S, Müller A, Burgmer R, Crosby RD, de Zwaan M, Legenbauer T. Health-related quality of life and psychological functioning 9 years after restrictive surgical treatment for obesity. Surg Obes Relat Dis. 2015;11(6):1361-70. Another rare long term follow up study looking at psychological functioning after bariatric surgery which found deteriorating mental health over time despite significant weight loss and initial improvement in psychosocial outcomes, inferring a need for postoperative psychosocial screening with referral to mental health professionals.

63. de Zwaan M, Enderle J, Wagner S, Mühlhans B, Ditzen B, Gefeller O. Anxiety and depression in bariatric surgery patients: a prospective, follow-up study using structured clinical interviews. J Affect Disord. 2011;133(1):61-8.

64. Booth H, Khan O, Prevost AT, Reddy M, Charlton J, Gulliford $\mathrm{MC}$, et al. Impact of bariatric surgery on clinical depression. Interrupted time series study with matched controls. J Affect Disord. 2015;174:644-9.

65. Dawes AJ, Maggard-Gibbons M, Maher AR, Booth MJ, MiakeLye I, Beroes JM, et al. Mental health conditions among patients seeking and undergoing bariatric surgery: a meta-analysis. JAMA. 2016;315(2):150-63.

66. Switzer NJ, Debru E, Church N, Mitchell P, Gill R. The impact of bariatric surgery on depression: a review. Curr Cardiovasc Risk Rep. 2016;10(3):1-5.

67. Canetti L, Bachar E, Bonne O. Deterioration of mental health in bariatric surgery after 10 years despite successful weight loss. Eur J Clin Nutr. 2016;70:17-22. This paper presents postoperative follow up results of up to 10 years in psychological functioning of bariatric patients in comparison to a dietary program participants. Although strongly recommended by the Bariatric Surgery research community, such long follow-up is very rare. 
68. Marek RJ, Ben-Porath YS, Ashton K, Heinberg LJ. Minnesota multiphasic personality inventory- 2 restructured form scale score differences in bariatric surgery candidates diagnosed with binge eating disorder versus BMI-matched controls. Int J Eat Disord. 2013. doi:10.1002/eat.22194.

69. Mitchell JE, Lancaster KL, Burgard MA, Howell LM, Krahn DD, Crosby RD, et al. Long-term follow-up of patients' status after gastric bypass. Obes Surg. 2001;11(4):464-8.

70. Gallant AR, Lundgren J, Drapeau V. The night-eating syndrome and obesity. Obes Rev. 2012;13(6):528-36.

71. Molin NB, Earthman CP, Cravo BS, Grotti CA, Landi MD, Farias $\mathrm{G}$, et al. Early effects of Roux-en-Y gastric bypass on peptides and hormones involved in the control of energy balance. Eur $\mathrm{J}$ Gastroenterol Hepatol. 2016.

72. Kalarchian MA, Marcus MD, Wilson GT, Labouvie EW, Brolin RE, La Marca LB. Binge eating among gastric bypass patients at long-term follow-up. Obes Surg. 2002;12(2):270-5.

73. Saunders R. Compulsive eating and gastric bypass surgery: what does hunger have to do with it? Obes Surg. 2001;11(6):757-61.

74. Saunders R. "Grazing": a high-risk behavior. Obes Surg. 2004;14(1):98-102.

75. Wood KV, Ogden J. Explaining the role of binge eating behaviour in weight loss post bariatric surgery. Appetite. 2012;59(1):177-80.

76. Scholtz, S., Miras, A. D., Chhina, N., Prechtl, C. G., Sleeth, M. L., Daud, N. M. \& Vincent, R. P. Obese patients after gastric bypass surgery have lower brain-hedonic responses to food than after gastric banding. Gut. 2013; gutjnl-2013.

77. Pepino MY, Bradley D, Eagon JC, Sullivan S, Abumrad NA, Klein S. Changes in taste perception and eating behavior after bariatric surgery-induced weight loss in women. Obesity. 2014;22(5):E13-20.

78. Wood KV, Ogden J. Predictors of decreased binge eating following laparoscopic adjustable gastric banding using the health action process approach model. Psychol Health Med. 2014;19(6):641-9.

79. Colles SL, Dixon JB. The relationship of night eating syndrome with obesity, bariatric surgery and physical health. In: Lundgren JD, Allison KC, Stunkard AJ, editors. Night eating syndrome. Research, assessment, and treatment. London: The Guilford Press; 2012. p. 85-107.

80. Zwaan M, Marschollek M, Allison KC. The night eating syndrome (NES) in bariatric surgery patients. Eur Eat Disord Rev. 2015;23(6):426-34.

81. Cash TF. Body image: past, present, and future. Body Image. 2004;1(1):1-5.

82. Grogan S. Body image: understanding body dissatisfaction in men, women and children. United Kingdom: Routledge; 2007.

83. Sarwer DB, Thompson JK, Cash TF. Body image and obesity in adulthood. Psychiatr Clin N Am. 2005;28(1):69-87. viii.

84. Markey CN, Markey PM. Relations between body image and dieting behaviors: an examination of gender differences. Sex Roles. 2005;53(7-8):519-30.

85. Schwartz MB, Brownell KD. Obesity and body image. Body Image. 2004;1(1):43-56.

86. Munoz DJ, Lal M, Chen EY, Mansour M, Fischer S, Roehrig M, et al. Why patients seek bariatric surgery: a qualitative and quantitative analysis of patient motivation. Obes Surg. 2007;17(11): 1487-91.

87. Song AY, Rubin JP, Thomas V, et al. Body image and quality of life in post massive weight loss body contouring patients. Obesity. 2006;14:1626-36.
88. Leombruni P, Pierò A, Dosio D, Novelli A, Abbate-Daga G, Morino M, et al. Psychological predictors of outcome in vertical banded gastroplasty: a 6 months prospective pilot study. Obes Surg. 2007;17(7):941-8.

89. Ortega J, Fernandez-Canet R, Alvarez-Valdeita S, Cassinello N, Baguena-Puigcerver M. Predictors of psychological symptoms in morbidly obese patients after gastric bypass surgery. Surg Obes Relat Dis. 2012;8(6):770-6.

90. Sarwer DB, Wadden TA, Moore RH, Eisenberg MH, Raper SE, Williams NN. Changes in quality of life and body image after gastric bypass surgery. Surg Obes Relat Dis. 2010;6(6):608-14.

91. van Hout GC, Hagendoren CA, Verschure SK, van Heck GL. Psychosocial predictors of success after vertical banded gastroplasty. Obes Surg. 2009;19(6):701-7.

92. Dixon JB, Dixon ME, O'Brien PE. Body image: appearance orientation and evaluation in the severely obese. Changes with weight loss. Obes Surg. 2002;12(1):65-71.

93. Teufel M, Rieber N, Meile T, Giel KE, Sauer H, Hünnemeyer K, et al. Body image after sleeve gastrectomy: reduced dissatisfaction and increased dynamics. Obes Surg. 2012;22(8):1232-7.

94. Sarwer DB, Thompson JK, Mitchell JE, Rubin JP. Psychological considerations of the bariatric surgery patient undergoing body contouring surgery. Plast Reconstr Surg. 2008;121(6):423e-34.

95. De Panfilis C, Cero S, Torre M, Salvatore P, Dall'Aglio E, Adorni A, et al. Changes in body image disturbance in morbidly obese patients 1 year after laparoscopic adjustable gastric banding. Obes Surg. 2007;17(6):792-9.

96. Bond DS, Phelan S, Leahey TM, Hill JO, Wing RR. Weight-loss maintenance in successful weight losers: surgical vs non-surgical methods. Int J Obes. 2009;33(1):173-80.

97. Pecori L, Cervetti GG, Marinari GM, Migliori F, Adami GF. Attitudes of morbidly obese patients to weight loss and body image following bariatric surgery and body contouring. Obes Surg. 2007;17(1):68-73.

98. Kitzinger HB, Abayev S, Pittermann A, Karle B, Bohdjalian A, Langer FB, et al. After massive weight loss: patients' expectations of body contouring surgery. Obes Surg. 2012;22(4):544-8.

99. Sarwer DB, Fabricatore AN, Jones-Corneille LR, Allison KC, Faulconbridge LN, Wadden TA. Psychological issues following bariatric surgery. Prim Psychiatry. 2008;15(8):50-5.

100.• McGrice M, Don Paul K. Interventions to improve long-term weight loss in patients following bariatric surgery: challenges and solutions. Diab Metab Syndr Obes. 2015;8:263-74. This review provides key recommendations for bariatric surgery practice aimed at improving long-term postoperative weight loss in patients, highlighting the importance of multidisciplinary working when managing this patient group.

101. Johnson SB. Increasing psychology's role in health research and health care. Am Psychol. 2013;68(5):311-21.

102. Bagdade PS, Grothe KB. Psychosocial evaluation, preparation, and follow-up for bariatric surgery patients. Diabetes Spectr. 2012;25(4):211-6.

103. Ames GE, Patel RH, Ames SC, Lynch SA. Weight loss surgery: patients who regain. Obes Weight Manage. 2009;5:154-61.

104. Adams TD, Davidson LE, Litwin SE, Kolotkin RL, LaMonte MJ, Pendleton RC, et al. Health benefits of gastric bypass surgery after 6 years. JAMA. 2012;308(11):1122-31. 